\title{
A spectacular case of penetrating craniocerebral trauma from a rake
}

\author{
Kaouther Somrani ${ }^{1}$, Mouna Rkhami ${ }^{2}$, Ghassen Gader $^{1}$, Aziz Bedioui ${ }^{1}$, and Ihsen Zammel ${ }^{1}$ \\ ${ }^{1}$ University of Tunis El Manar Faculty of Medicine of Tunis \\ ${ }^{2}$ University of Tunis El Manar
}

March 5, 2022

\begin{abstract}
We present a case of a 30-years-old man who was victim of aggression with a rake blow to the head. The surgery was delicate since two of the rake's teeth plunged into the superior sagittal sinus. Postoperatively, the patient was discharged with only a right upper limb monoparesia.
\end{abstract}

\section{A spectacular case of penetrating craniocerebral trauma from a rake}

\section{Abstract}

We present a case of a 30-years-old man who was victim of aggression with a rake blow to the head. The surgery was delicate since two of the rake's teeth plunged into the superior sagittal sinus. Postoperatively, the patient was discharged with only a right upper limb monoparesia.

Keywords: craniocerebral trauma, penetrating trauma, foreign body, surgery, craniotomy

\section{Acknowledgements:}

None

\section{Message clinical key:}

Penetrating head injuries are associated with a high incidence of morbidity and mortality. The main risks are infectious and thromboembolic especially when the sinus is injured. Specific surgery management must be studied in every case to avoid worsening brain damages.

\section{Introduction:}

Penetrating craniocerebral trauma, although uncommon, has a high potential for death or serious morbidity due to injury of vital neurovascular structures. When an object remains embedded, additional issues arise, and careful assessment and management of any injuries and their sequelae, are required to minimize morbidity and mortality. ${ }^{[8]}$

We present a case of penetrating cranial trauma from a rake that remained in situ.

\section{Case presentation:}

A 30-years-old man with no medical history was victim of aggression with a rake blow to the head. The rake's teeth were embedded into the cranium (Figure 1 and 2). The patient had a Glasgow coma scale of 14/15, without motor deficit, the rake teeth were inserted diagonally into the vertex (Figure 1 and 2). Brain scan was performed but due to the difficult positioning of the head at the scanner head, reconstructions showed a significant depression through the skull and the parenchyma, with significant artefact. Parenchymal lesions were difficult to establish. 
The patient was intubated, and referred to Neurosurgery department.

In the operating room, after 4 hours from the injury, the patient was placed in prone position, with the head fixed by a bone-gripping headpiece. The civil protection service intervened to cut the branches of the rake with a metal cutting saw, leaving the 4 separate teeth of the rake pressed into the skull (Figure 3 ). The teeth of the rake were firmly embedded to the skull. Their section with the electric saw could not generate any movement. An incision was made along the 4 teeth (Figure 4). Then we performed four mini-craniectomies around each tooth (Figure 5). The 2 parasagittal teeth were easily removed. The 2 medial teeth plunge $2 \mathrm{~cm}$ into the superior sagittal sinus (SSS). Their ablation results in abundant venous bleeding requiring clipping with Mackenzie clips, tamponade and dura patching with pericranium.

The 4 dural breaches were closed by pericranial plasties reinforced with biological glue (Figure 6). Cranioplasty was delayed due to the risk of sepsis.

The patient was admitted to intensive care. No preventive antibiotic were used, except one dose of Amoxicillin/clavulanic acid (2g) before the incision. Control CT scan showed an endoluminal defect of the superior sagittal sinus advocating local thrombosis, with no other associated lesions (Figure 7).

The patient was placed on curative anticoagulation and was extubated at D9 postoperatively. He was conscious and had a right upper limb monoparesia. He presented ventilator-acquired pneumonia and was put on antibiotics with good progression. He was discharged after 15 days of hospitalization (Video 1).

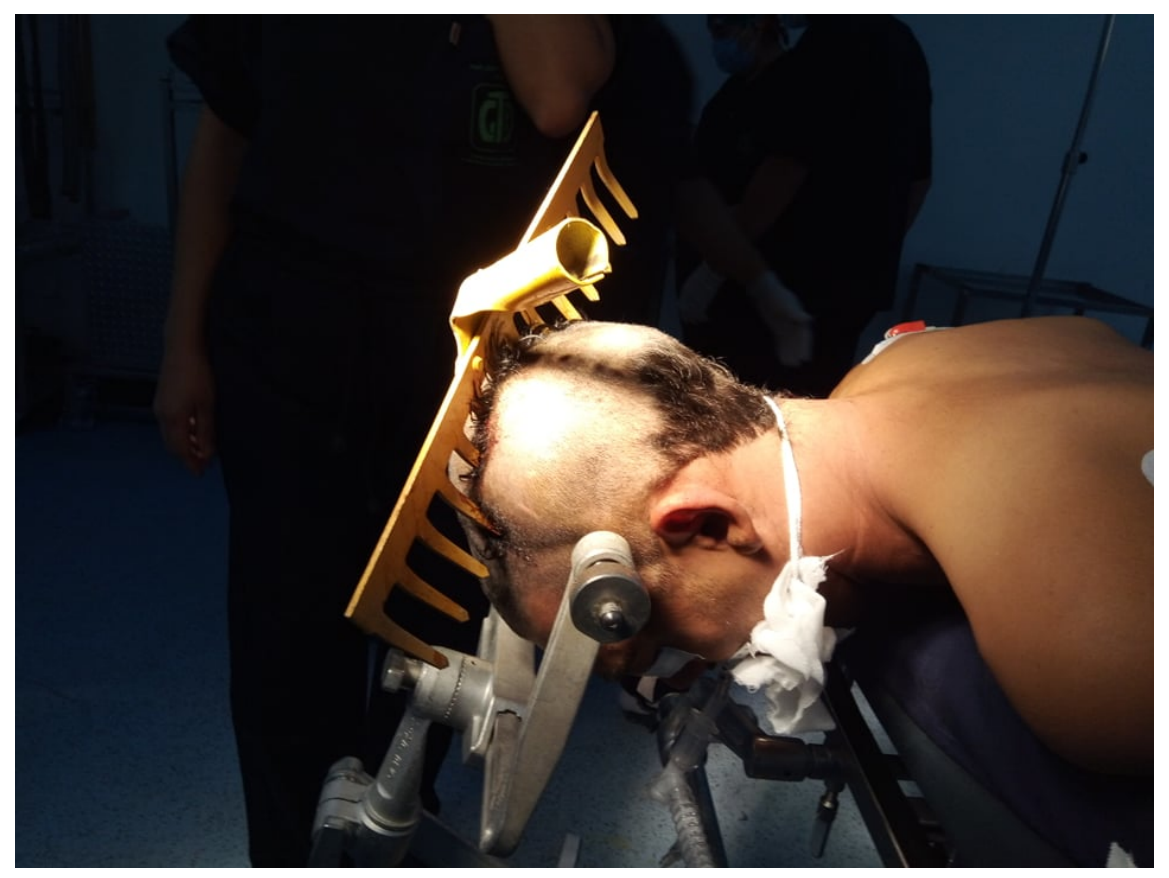




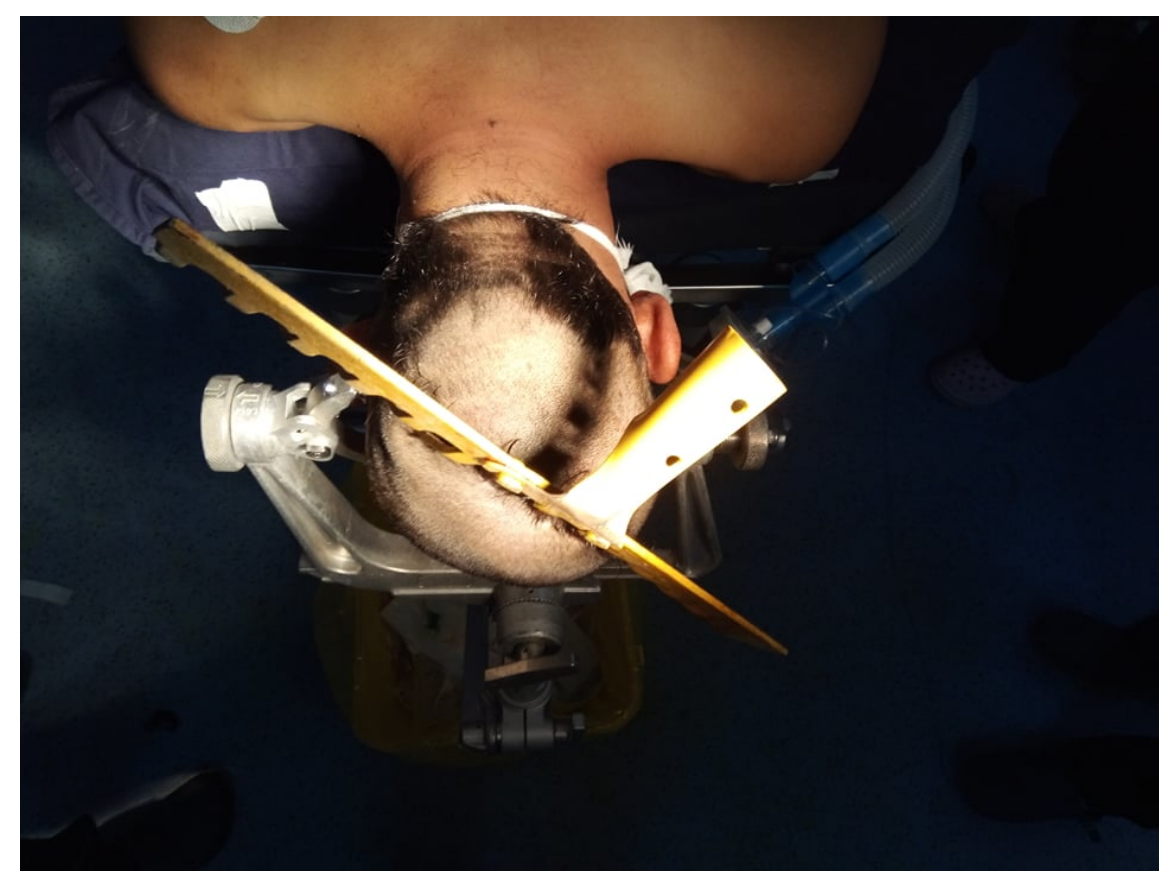

Figure 1 and 2: Preoperative photos showing the penetrating rake

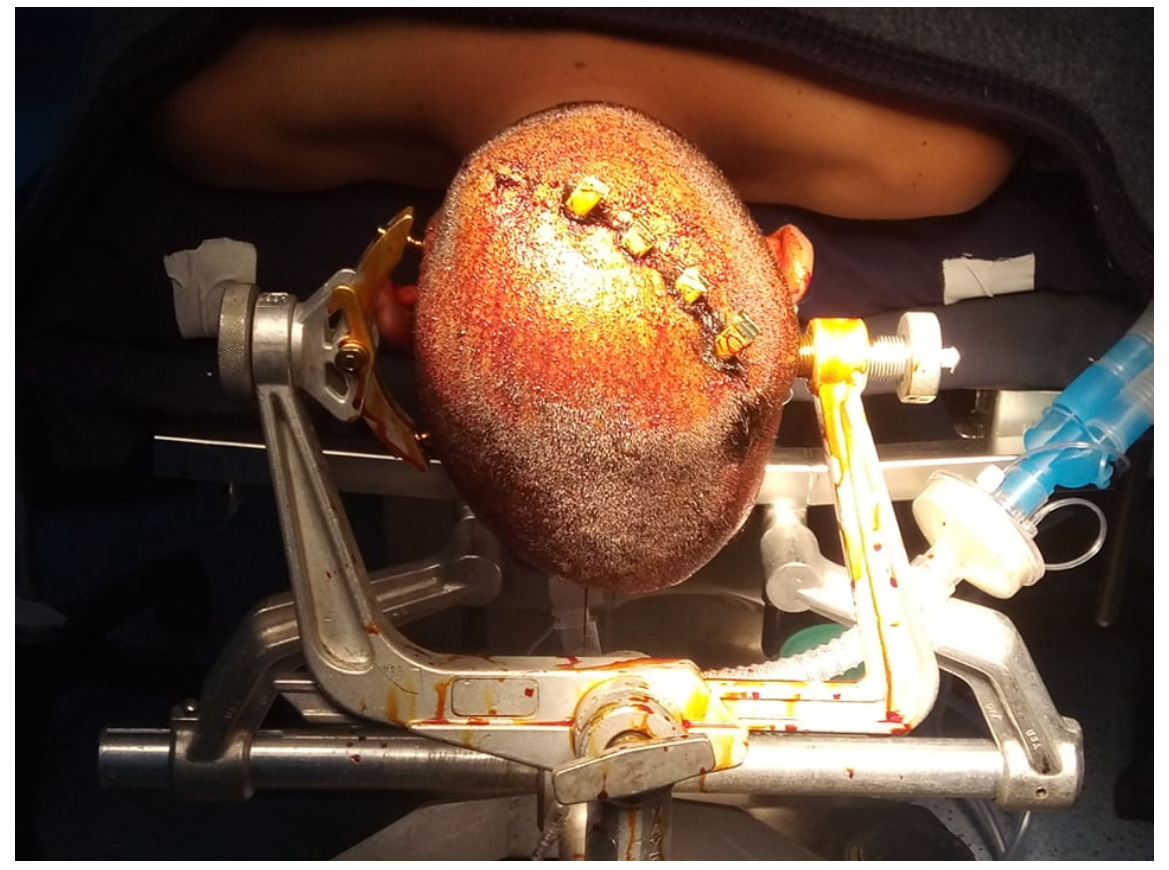

Figure 3: Preoperative photo showing the rake after its cutting with the 4 teeth embedded into the skull 


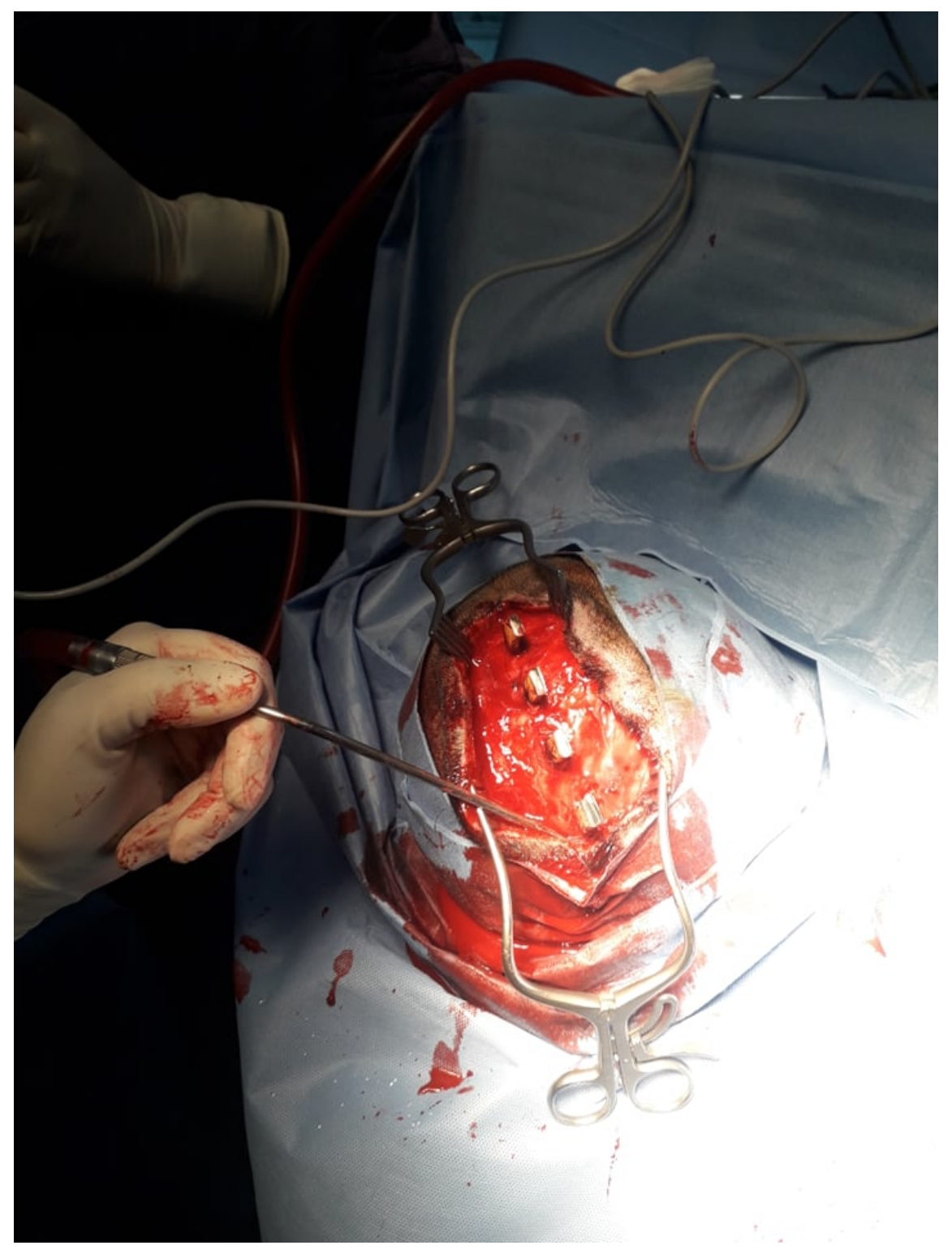

Figure 4: Perioperative photo showing the 4 teeth inserted to the skull after linear incision 


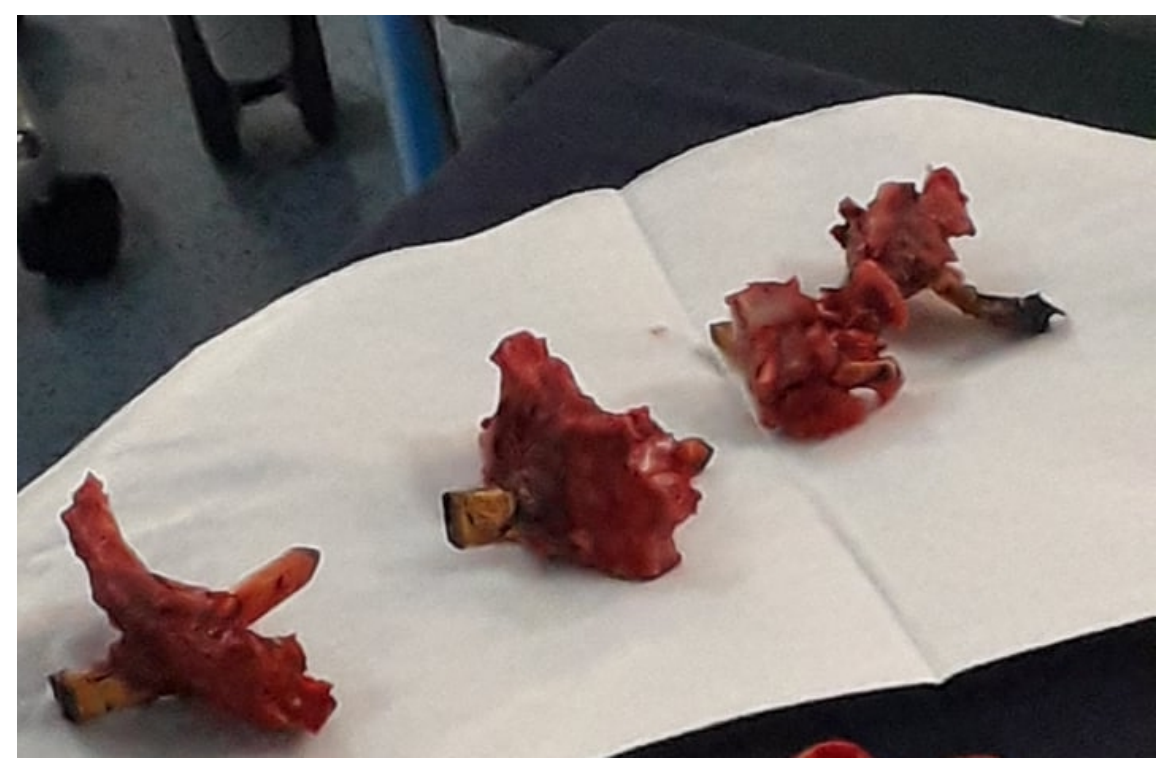

Figure 5: Photo showing the four mini craniectomies performed around each tooth 


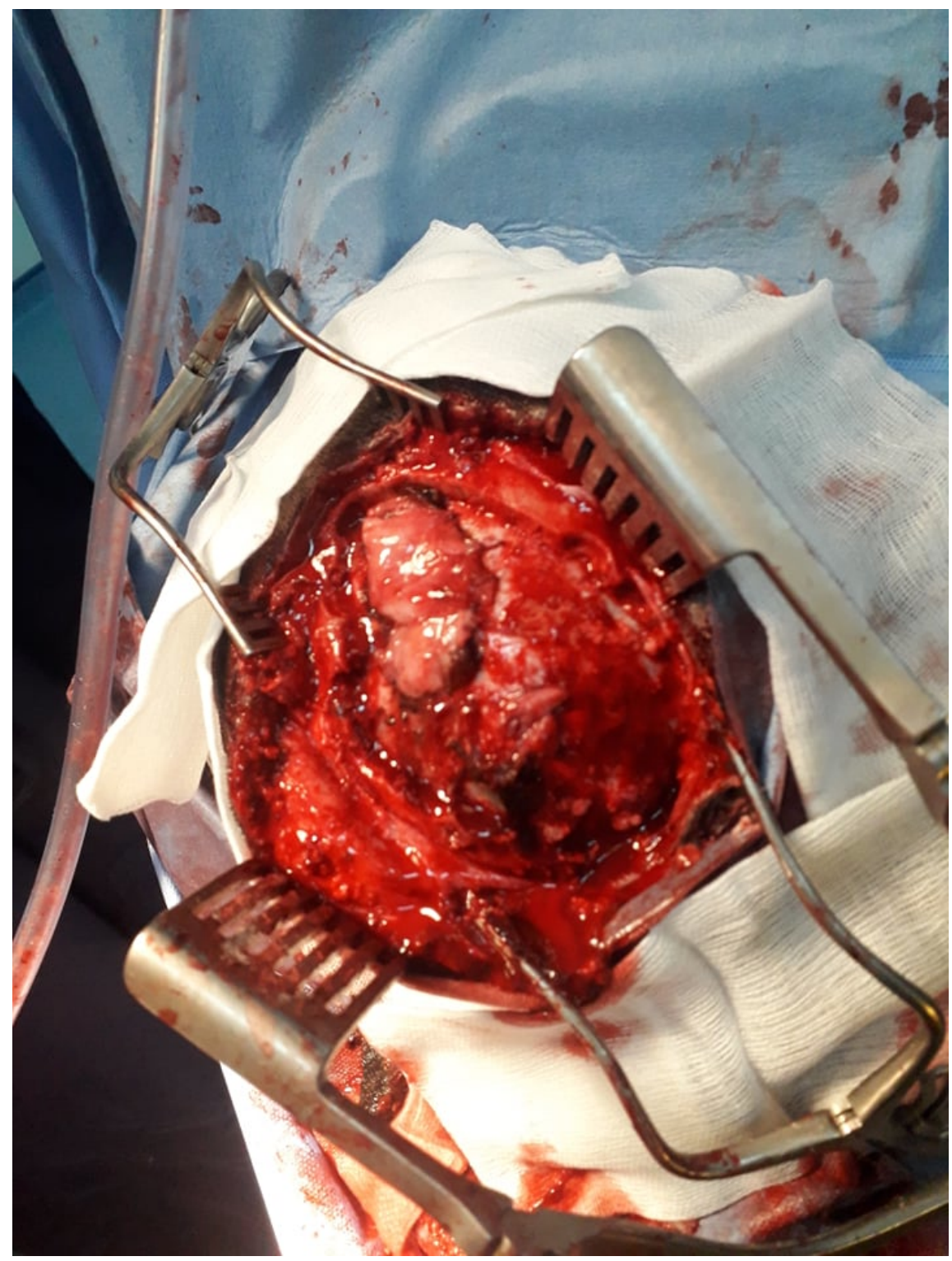

Figure 6: Perioperative photo showing the bone defect and the dura mater after its plastic repair 


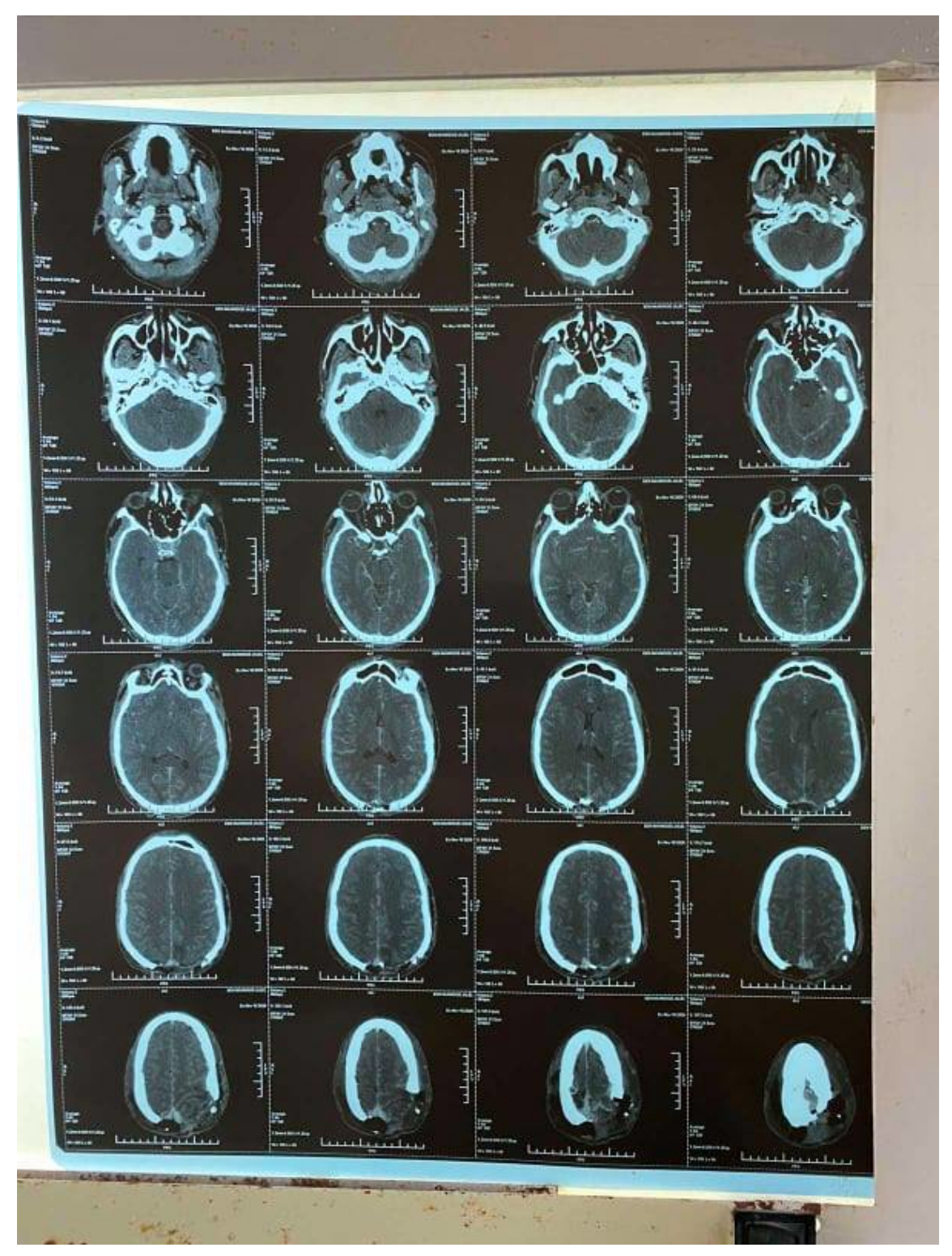

Figure 7: Post-operative CT scan

\section{Discussion:}

Penetrating intracranial foreign bodies are rare, especially in civilian practice. A literature review showed that penetrating intracranial injuries account for less than $0.4 \%$ of all traumatic head injuries and have a high mortality and morbidity rate. ${ }^{[1]}$

Only few studies have reported on the removal of such foreign bodies, especially in cases where the foreign body is close to, or penetrates the superior sagittal sinus.

Cases have been reported by various authors of suicidal or homicidal incidences ${ }^{[2]}$, where patients were inflicted injury by means of nails and other objects. Other circumstances were reported such as road, domestic, ${ }^{[3]}$ or work accident. ${ }^{[4]}$

They cause a spectacular cranial trauma, all the more the object is voluminous. The goal of the surgery is 
to remove the object without worsening the parenchymal and vascular cerebral lesions already present.

This manoeuvre is delicate. It is recommended to perform a craniectomy around the penetrating object, then carefully extract it with or without opening the dura mater. This allows to control a possible parenchymatous or dura mater bleeding, in particular an injury of the venous sinuses. ${ }^{[5]}$

The particularity of our case is that the rake was constituted by four teeth that were embedded in the parenchyma. The extraction needed to remove each tooth separately. So, we had to perform circular mini craniectomies around each tooth.

Other authors recommend to do $\mathrm{D}^{[6]}$ or $\mathrm{U}^{[7]}$ shaped craniectomy in cases of single foreign sharp embedded object.

The complications of such penetrating trauma are primarily infectious, namely meningitis, meningoencephalitis, and cerebral abscess, secondly vascular such as cerebral thrombophlebitis due to traumatic or postoperative sinus injury. ${ }^{[8][9]}$ It is recommended in this case to put the patient on curative anticoagulation 48 hours postoperatively after eliminating an haemorrhagic complication. ${ }^{[9]}$

\section{Conclusion:}

Penetrating head injuries are dreadful casualties associated with a high incidence of morbidity and mortality. The main risks are infectious and thromboembolic especially when the sinus is injured.

Disclosure Statement: Neither of the authors has any conflict of interest to disclose

Declaration of patient consent:The authors certify that they have obtained all appropriate patient consent forms. In the form the patient has given his consent for his images and video and other clinical information to be reported in the journal. The patient understand that his name and initials will not be published and due efforts will be made to conceal his identity.

\section{Acknowledgements:}

None

\section{Author contributions:}

K Somrani and M Rkhami participated in diagnosing treating the patient and acquisition of data.

A Bedioui and K Somrani collected the findings and drafted the manuscript.

M Rkhami and I Zammel revised the manuscript.

The authors read and approved the final manuscript.

The integrity of this work is guaranteed by Dr. Kaouther Somrani and Pr. Ihsen Zammel

\section{References :}

1. Rosenfeld JV, Bell RS, Armonda R. Current Concepts in Penetrating and Blast Injury to the Central Nervous System. World J Surg. 1 juin 2015;39(6):1352-62.

2. Kishore K, Sahu S, Bharti P, Dahiya S, Kumar A, Agarwal A. Management of unusual case of self-inflicted penetrating craniocerebral injury by a nail. J Emerg Trauma Shock. 2010;3(2):193-6.

3. Kjelland C, Thirsk W. Penetrating craniofacial trauma from a vice clamp: case report and discussion. CJEM. janv 2011;13(01):57-61.

4. Vakil MT, Singh AK. A review of penetrating brain trauma: epidemiology, pathophysiology, imaging assessment, complications, and treatment. Emerg Radiol. juin 2017;24(3):301-9.

5. Chowdhury FH, Haque MR, Hossain Z, Chowdhury NK, Alam SM, Sarker MH. Nonmissile Penetrating Injury to the Head: Experience with 17 Cases. World Neurosurg. oct 2016;94:529-43. 
6. Miki K, Natori Y, Kai Y, Mori M, Yamada T, Noguchi N. How to Remove a Penetrating Intracranial Large Nail. World Neurosurg. juill 2019;127:442-5.

7. Guppy KH, Ochi C. Self-Inflicted Drywall Screws in the Sagittal Sinus. World Neurosurg. févr $2018 ; 110: 323-5$.

8. Enam S, Kazim S, Tahir M, Waheed S, Shamim M. Management of penetrating brain injury. J Emerg Trauma Shock. 2011;4(3):395.

9. Department of Neurosurgery, Pamela Youde Nethersole Eastern Hospital, Chai Wan, Hong Kong, Chan S, Pang K, Wong C. Transnasal penetrating intracranial injury with a chopstick. Hong Kong Med J. 29 janv 2014;20(1):67-9.

\section{Hosted file}

Figure file.docx available at https://authorea.com/users/463647/articles/558701-aspectacular-case-of-penetrating-craniocerebral-trauma-from-a-rake 